$\Phi=$

\title{
Prevalence of developmental anomalies of teeth in a group of North Karnataka population, India
}

\author{
Rajeshwari Javali $^{1 *}$, Mangala Meti $^{2}$ \\ ${ }^{1}$ Senior lecturer, Department of Oral Medicine and Radiology, S.B. Patil Dental College and Hospital, Bidar, Karnataka, India \\ ${ }^{2}$ Professor and Head, Department of Oral Medicine and Radiology, Coorg Institute of Dental Sciences, Virajpet, Karnataka, India \\ *Corresponding author E-mail: paradise_903@yahoo.com
}

\begin{abstract}
Aims and objective: To assess the prevalence of the developmental dental anomalies like disturbances in size, shape, structure, eruption pattern and number in a group of North Karnataka population and to assess the dental anomalies in patients with head and neck syndrome. Method: A cross-sectional prospective survey was carried out at P.M.N.M Dental College and Hospital, Bagalkot, North Karnataka, India during the academic year, November 2011 to August 2013 to study the prevalence of various developmental dental anomalies of teeth in a population of 3000 patients aged between 10 to 30 years in both genders. Patients were screened clinically for the presence of dental anomalies with appropriate radiographs and dental casts.

Result: Of 3000 patients screened, 477 had developmental dental anomalies. Out of these, 254 were males and 223 were females. The most commonly found anomalies were impacted teeth, hypodontia, dental fluorosis, overretained, supernumerary teeth, talon's cusp with the least being dentinogenesis imperfecta (none).

Conclusion: The significance of conducting such a study is, that if the dental anomalies are detected earlier, the consequences (like early pulp involvement in dens-in-dente, malocclusion) can be intervened and treated accordingly. This study hence provides an useful data regarding the prevalence of the most and the least common anomalies in North Karnataka region of India.
\end{abstract}

Keywords: Anomalies; Developmental Defects; India; Prevalence; Teeth.

\section{Introduction}

The developing tooth is a biological recorder providing a precise and permanent record of the variations and fluctuations in the tooth matrix and its mineralization. Disturbances during various stages of tooth development can markedly alter the number, size, shape, structure, color and eruption pattern of the teeth. These disturbances may also show wide normal and biological variations within and among different populations of the world. The abnormal variations that occur in relation to the dentition and jaws could be attributed to the genetic, environmental, social, ethnic and pathological factors. Dental anomalies are a frequent finding on routine oral examination.

Some of the dental malformations can be detected on radiographic screening. Various radiographic protocols have been proposed to screen for asymptomatic pathologic and developmental conditions that are not apparent on a clinical examination. The logic in screening radiographs is that the radiation risk will be justified by the early identification of a reasonably significant number of treatable conditions. This plays a vital role in reducing the morbidity associated with anomalies in structure namely den's invaginatus and impacted teeth.

The anomalies of the teeth may be inherited or acquired. They may be either localized to single tooth or generalized to involve the entire dentition. The various dental disturbances can create disturbances in the maxilla and mandibular arch lengths, occlusions and can lead to aesthetically compromised conditions further complicating the orthodontic treatment planning and aesthetics corrections. Though the prevalence of anomalies is comparatively less than the common oral diseases like dental caries and periodontal diseases, but the challenges that accompany the clinical management is noteworthy.

Many epidemiological surveys have been conducted across the globe to determine the prevalence of various types of dental anomalies.

The objective of this study was to assess the prevalence of the developmental dental anomalies like disturbances in size, shape, structure, eruption pattern and number in a group of Bagalkot population including patients with head and neck syndromes.

\section{Materials and method}

A cross sectional prospective survey was carried out during the academic year, November 2011 to August 2013 to study the prevalence of various dental anomalies in a population of 3000 patients aged between 10 to 30 years in both genders. The sample represented $20 \%$ of the patients visiting the Department of Oral Medicine and Radiology and 200 dental students, P.M.N.M Dental College and Hospital, Bagalkot, North Karnataka, India. The study included 1719 males and 1281 females.

For a comprehensive clinical examination an individual was seated on a dental chair and examined under good chair light with a dental mouth mirror and probe. Patients were clinically and radiographically explored during routine examination following demographic data collection and recorded on a systematic proforma. Personal and family histories were also recorded. 
Anomalies single or combined were thoroughly examined. Pretreatment dental casts, intra-oral photographs, radiographs and panoramic images were made whenever needed.

The following dental anomalies were assessed:

1) Disturbances in size (macrodontia \& microdontia).

2) Disturbances in shape (concrescence, dens-in-dente, dens evaginatus, dilaceration, fusion, gemination, supernumerary roots, talon's cusp \& taurodontism).

1) Disturbances in a number (anodontia, hypodontia \& supernumerary teeth).

2) Disturbances in structure (amelogenesis imperfecta, dentinogenesis imperfecta, dentin dysplasia, enamel hypoplasia \& dental fluorosis).

Inclusion criteria:

1) Subjects with developmental dental anomalies in shape, size, number, structure and eruption were included.

2) Syndromic patients with multiple dental anomalies were included.

Exclusion criteria:

1) Teeth missing as a result of caries, periodontal disturbances, and trauma/extraction were excluded from the study.

2) Patients with significant systemic medical history, trauma to joints, metabolic disorders, extractions before orthodontic treatment and patients who received previous orthodontic treatment were also excluded.

Radiographic examination of conventional intraoral, occlusal and digital panoramic radiographs were meticulously observed by an experienced radiologist using magnifying lens and $\mathrm{X}$ ray viewers in an ambient atmosphere, and findings were interpreted and recorded.

\section{Results}

The findings of the study were analyzed by using Statistical Package for Social Sciences (SPSS) version 20. Chi-square test was used for statistical analysis. In this cross sectional prospective study, the sample group comprised of 3000 patients who represented $20 \%$ of the patients attending the outpatien department of Oral Medicine and Radiology, P.M.N.M Dental College and Hospital, Bagalkot, North Karnataka, India.

Out of 3000 patients, $1352(45.07 \%)$ were in the age group of 10 to 20 years and $1648(54.93 \%)$ were in the age group of 21 to 30 years. About $477(15.9 \%)$ patients had dental anomalies and $2523(84.1 \%)$ had no developmental dental anomalies.
A total of 1719 males and 1281 females were screened for the dental anomalies, and 254 were males and 223 were females accounting for a total of 477 patients. $1465(85.22 \%$ ) of males and $1058(82.59 \%)$ of females had no developmental dental anomalies. The presence of anomalies was a statistically significant finding $(\mathrm{p}<0.0512)$ in the sample included for the study.

Various developmental dental anomalies found in 3000 study population are listed in table 1 .

Table 1: Distribution of Anomalies in the Study Population

\begin{tabular}{lll}
\hline Anomaly & Number of patients & Percentage \\
\hline Macrodontia & 7 & 0.23 \\
Microdontia & 50 & 1.67 \\
Amelogenesis imperfecta & 6 & 0.20 \\
Dentinogenesis imperfecta & 0 & 0.00 \\
Dentin dysplasia & 5 & 0.17 \\
Dental fluorosis & 98 & 3.27 \\
Concrescence & 1 & 0.03 \\
Dens in dente & 12 & 0.40 \\
Dens evaginatus & 4 & 0.13 \\
Dilaceration & 30 & 1.00 \\
Fusion & 5 & 0.17 \\
Gemination & 3 & 0.10 \\
Supernumerary roots & 3 & 0.10 \\
Talon's cusp & 54 & 1.80 \\
Taurodontism & 9 & 0.30 \\
Hypodontia (excluding 3rd molars) & 60 & 2.00 \\
Hypodontia with only 3rd molar & 37 & 1.23 \\
Hypodontia including 3rd molar & 10 & 0.33 \\
Supernumerary teeth & 44 & 1.47 \\
Impacted supernumerary & 16 & 0.53 \\
Ankylosed deciduous & 14 & 0.47 \\
Delayed eruption & 6 & 0.20 \\
Impacted teeth & 42 & 1.40 \\
Impacted 3rd molar & 78 & 2.60 \\
Over retained & 97 & 3.23 \\
\hline
\end{tabular}

Prevalence of anomalies as generalized conditions is as follows: Microdontia 2(0.07\%), amelogenesis imperfecta $6(0.20 \%)$, dentin dysplasia 5(0.17\%), dental fluorosis $98(3.27 \%)$, oligodontia $4(0.13 \%)$ and enamel hypoplasia $1(0.03 \%)$ (Table $2 \&$ graph 1$)$

Table 2: Prevalence of Anomalies as Generalized Conditions

\begin{tabular}{lll}
\hline Anomaly & No of patients & Prevalence /percentage \\
\hline Microdontia & 2 & 0.07 \\
Amelogenesis imperfecta & 6 & 0.20 \\
Dentinogenesis imperfecta & 0 & 0.00 \\
Dentin dysplasia & 5 & 0.17 \\
Dental fluorosis & 98 & 3.27 \\
Oligodontia & 4 & 0.13 \\
\hline
\end{tabular}

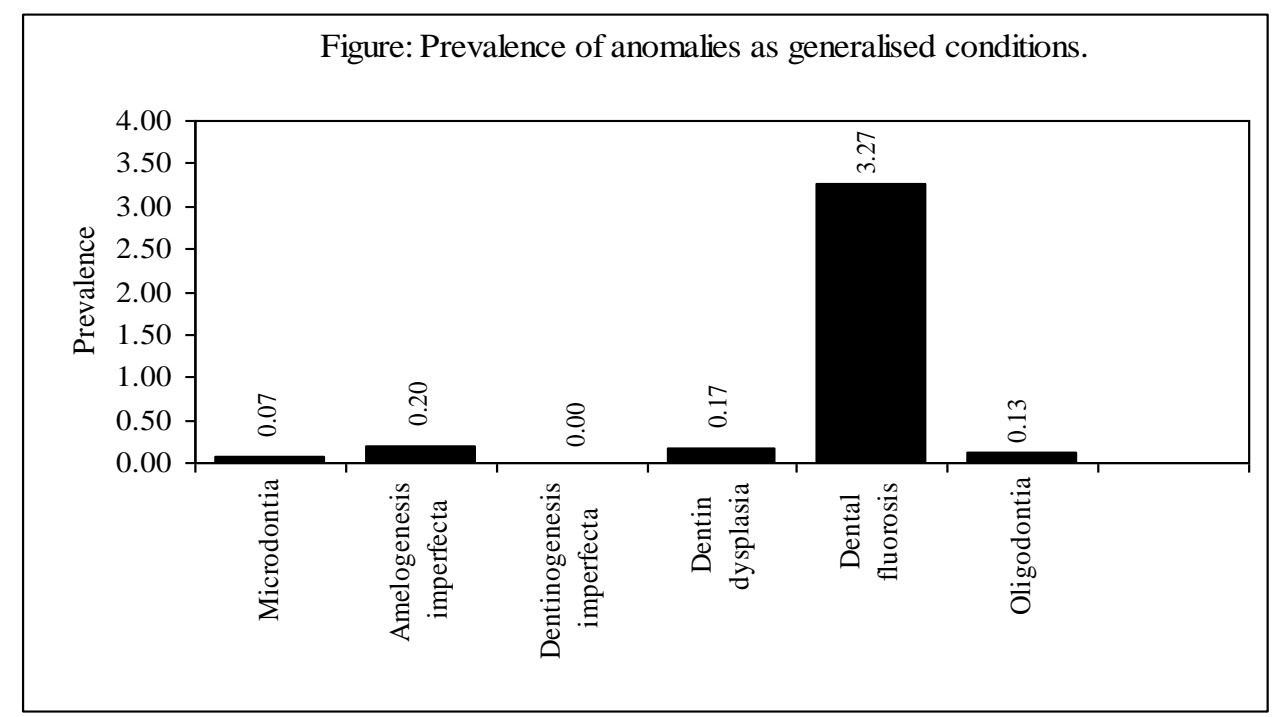

Fig. 1: Prevalence of Anomalies as Generalized Conditions. 
Few anomalies were seen in the midline like talon's cusp$1(0.03 \%)$, dilaceration- $1(0.03 \%)$ and mesiodens-25(0.83\%)

Table 3 and Graph 2 demonstrates the distribution of anomalies as follows; 57 (1.90\%) had disturbances in size, 110(3.67\%) had disturbances in structure, 121(4.03\%) showed disturbances in shape, $171(5.70 \%)$ disturbances in number and 140(4.67\%) had disturbances in eruption.
Table 3: Distribution of Patients with Prevalence of Anomalies

\begin{tabular}{lll}
\hline Anomalies & Frequency & Prevalence \\
\hline Disturbance in size & 57 & 1.90 \\
Disturbance in shape & 121 & 4.03 \\
Disturbance in structure & 110 & 3.67 \\
Disturbance in number & 171 & 5.70 \\
Disturbance in eruption & 140 & 4.67 \\
\hline
\end{tabular}

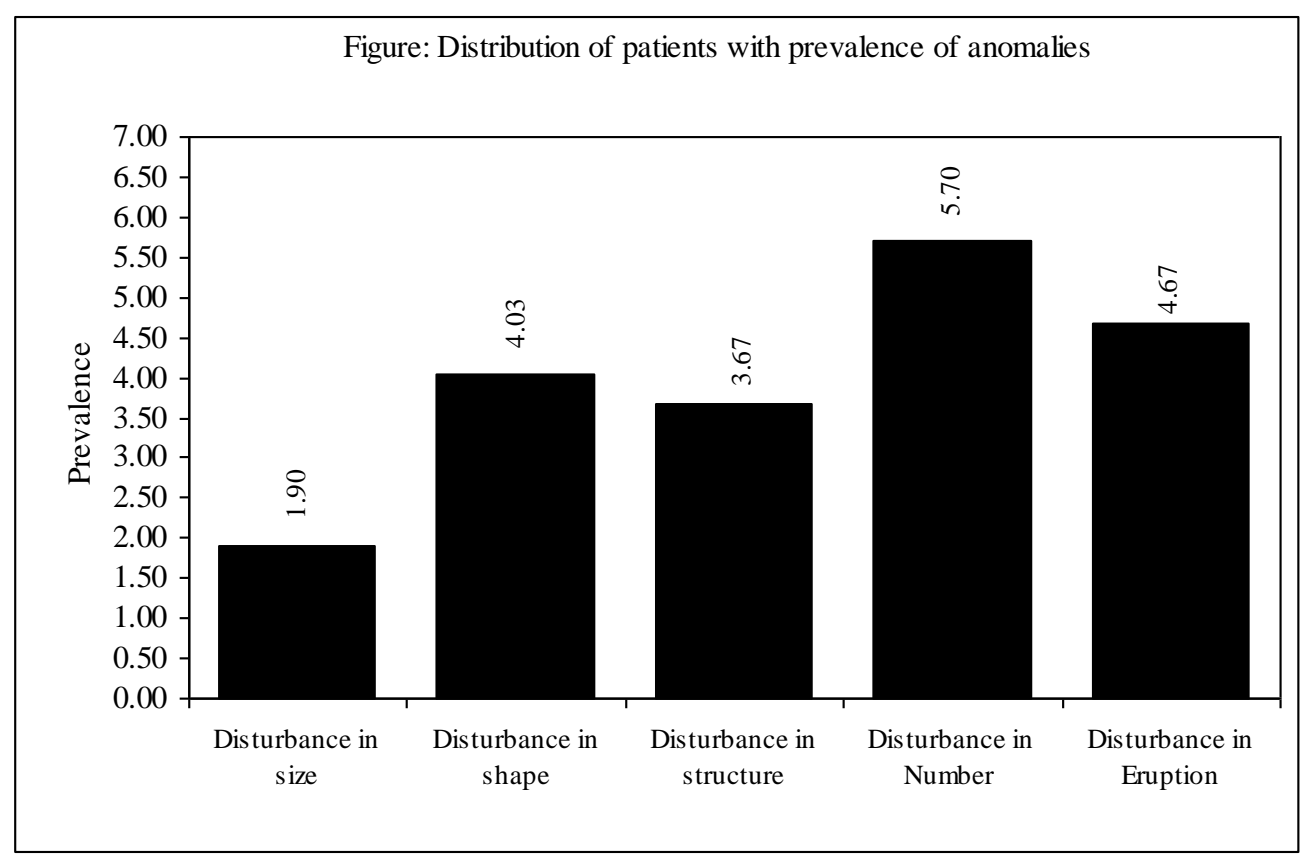

Fig. 2: Distribution of Patients with Prevalence of Anomalies.

\section{Discussion}

Several epidemiological studies have been carried out to record the prevalence of the developmental dental anomalies in different geographical areas across the globe and have shown wide variations in the prevalence percentage, anomaly distribution with respect to gender, arch and quadrant. The discrepancies in the various results have been attributed to the racial differences, variable sampling techniques and different diagnostic criteria (Kositbowornchai $\mathrm{S}$ et al. 2010)

No such epidemiological study has been carried out to record all the developmental dental anomalies in Bagalkot, North Karnataka, India. Hence, this was chosen as the geographical study area of interest.

Macrodontia: when teeth are physically larger than usual. In addition, the term macrodontia should not be used to describe teeth that have been altered by fusion or gemination. In our study only $7(0.23 \%)$ had macrodontia. This prevalence is lower than the studies done in the population of Saudi Arabia(Ghaznawi HI et al. 1999), Japan(Ooshima T et al.1996), South China(King et al. 2010) and Thai( Kositbowornchai $S$ et al. 2010) population and greater than that found in Turkey(Altug-Atac et al. 2007) and Chennai(Kayal L et al. 2011).

Microdontia commonly found in maxillary lateral incisors and third molars. When lateral incisors are affected, there is a reduction in mesiodistal diameter and convergence towards the incisal edge and this is referred as peg shaped incisors. In our study 50 patients with a prevalence of $1.67 \%$ presented with microdontia which was also a finding closer to another study conducted by Altug-Atac AT et al. 2007.

Amelogenesis imperfecta is a diverse group of hereditary conditions that primarily affects the quality and or the quantity of dental enamel. In this study, amelogenesis imperfecta (AI) was evaluated without dividing the cases into subgroups as done by another author (Gupta et al.2011). The prevalence varies from $0.007 \%$ (Kayal L et al. 2011) to $0.43 \%$ with our study showing a prevalence of $0.20 \%$, which is similar to the study conducted by Sener S et al $2011(0.2 \%)$.

Dental fluorosis is caused due to ingestion of excess amounts of fluoride which can result in significant enamel defects or hypoplasia. A prevalence of $3.27 \%$ for dental fluorosis was found in our study but however, this finding is lower than those reported by few authors in different population groups like Iran(7.72\%)(Ghabanchi J et al. 2010) and India(18.8\%)( Nayak P et al. 2011)

Dentin dysplasia (DD) is an autosomal dominant hereditary disturbance in dentin formation, which may present with either mobile teeth or pain associated with spontaneous dental abscesses or cysts. Our study showed a prevalence of $0.17 \%$ which was higher in females $(0.23 \%)$ than males $(0.12 \%)$.

Concrescence is the union of two separate tooth buds after crown development is completed; the roots are connected by cementum. In this study concrescence constituted of only 1 subject with prevalence of $0.03 \%$ which is less than that compared with a study conducted by Guttal SK et al who gave a prevalence of $1.4 \%$.

Dens in dente is a developmental variation which is thought to arise as a result of invaginatus in the surface of the tooth crown before calcification has occurred. We found 12 cases of dens-indente with a prevalence of $0.4 \%$, which is a finding in agreement with the study conducted by King et al in South China (0.4\%). The prevalence of den's invaginatus ranged from $0.03 \%$ (Kayal L et al. 2011) to $1.5 \%$ (Şener S et al. 2011).

Den's evaginatus is a developmental condition that appears clinically as an accessory cusp. The tooth may remain 
asymptomatic for a considerable period of time. In the present study den's evaginatus comprised of $0.13 \%$ of all dental anomalies. The prevalence range for this anomaly is $0.01 \%$ (Kayal L et al. 2011) to $8.6 \%$ (Cho Y S et al. 2008).

Dilaceration is thought to arise secondary to trauma during tooth formation, altering the angle between the tooth germ and the portion of the tooth already developed. The prevalence of dilaceration in our study is $1 \%$. The prevalence ranges from $0.02 \%$ (Goya HA et al. 2008) to 22.5\% (Berrocal et al. 2007) .However few studies in India showed much higher prevalence rates (Guttal et al.2010 \& Vibhute et al. 2013).

Fusion of teeth arises through union of two normally separated tooth germs. Our study showed a prevalence of $0.17 \%$ which is in accordance with the study conducted by a few authors in Thai( Kositbowornchai S et al. 2010) and Turkey( Şener S et al. 2011 ) respectively. The prevalence ranges from $0.03 \%$ (Kayal L et al. 2011) to $4.8 \%$ (Guttal et al. 2010).

Geminated teeth are anomalies which arise from an attempt at division of a single tooth germ by an invagination, with resultant incomplete formation of two teeth. The present study shows a prevalence of $0.10 \%$ which is in close association with a study conducted by Buenviaje et al. 1984 with a prevalence of $0.08 \%$. The prevalence ranges from $0.01 \%$ to $0.4 \%$ ( Şener S et al. 2011).

Supernumerary roots are accessory roots. Not many studies have been reported with a prevalence of accessory roots except for individual case reports. We, however, report the prevalence of supernumerary roots to be $0.1 \%$.

Talon's cusp is an accessory cusp in cingulum area of anterior teeth. In our study the prevalence was $1.80 \%$. Higher prevalence rates were shown by few (Guttal 2010, Şener S 2011 \& Vibhute 2013) and lower by other studies (Nayak 2011, Gupta 2011 \& Kayal 2011).

Taurodontism term was coined to describe a peculiar dental anomaly in which the body of the tooth is enlarged at the expense of the roots. The highest prevalence was 18\% (Guttal et al. 2010). In our study, the prevalence was noted to be $0.30 \%$, which is in accordance with studies conducted in Turkey (Şener S et al. 2011) and in Saudi Arabia (Ghazanawi et al. 1999).

Hypodontia denotes the lack of development of one or more teeth We report a prevalence of $3.23 \%$, which is lower than that reported in the United States (Clayton et al. 1956) and higher prevalence than that reported by India (Kayal L et al. 2011).

Supernumerary teeth are defined as teeth additional to the normal dentition. Our results $(1.47 \%)$ were in coincidence with the findings done by various authors (Ghazanawi 1999 \& Berrocal 2007) and higher prevalence rates was seen in studies carried out in United States (2.24\%) (Clayton et al. 1956) and in Turkey (2.3\%) ( Şener S et al. 2011).

Ankylosed deciduous teeth are submerged teeth. In our study, the prevalence of ankylosed deciduous teeth was $0.47 \%$. Not many studies are there that have reported the prevalence of ankylosed deciduous teeth accept for the case reports on management of ankylosed deciduous teeth.

Delayed eruption : all the teeth that have not erupted six months after its normal eruption time should be considered as delayed. The prevalence of delayed eruption in our study is $0.20 \%$ which is greater than a study conducted by Kayal $0.08 \%$ (Kayal L et al 2011).

Impacted teeth are those prevented from erupting by some physical barrier in the eruption path. The prevalence of impacted teeth excluding third molars in our study was $1.40 \%$ and impacted third molar was $2.60 \%$

Over the retained tooth is a condition in mixed dentition phase when the primary tooth has not shed yet whereas the succedaneous tooth has erupted. In this study the prevalence of over retained teeth was $3.23 \%$ in contrast to $20.85 \%$ by Lestari Z.D et al.

The frequency of single dental anomalies in patients was more compared to multiple dental anomalies. Many of the studies conducted by various authors have excluded the syndromic patients from their studies, but our study included the patients with anomalies having dental manifestations.

\section{Conclusion}

Our study was an attempt to evaluate the prevalence of various developmental dental anomalies occurring in Indian population, especially North Karnataka region, India. Varied results have been reported for different population across the globe and various group of Indian population. The frequency of dental anomalies has been known to have wide geographical, racial and ethnic variation. The significance of conducting such a study is, that if the dental anomalies are detected earlier, the consequences (like early pulp involvement in dens in dente, malocclusion) can be intervened and treated accordingly.

Our study reports a higher prevalence of impacted teeth, hypodontia, dental fluorosis, over retained teeth, supernumerary teeth, talon's cusp and microdontia whereas lower prevalence of amelogenesis imperfecta, dentin dysplasia, concrescence, dens evaginatus, fusion, gemination, supernumerary roots and taurodontism. The prevalence of dental anomalies found was equally distributed between the gender except for hypodontia and supernumerary teeth, which showed an increased female predilection. Microdontia, dilaceration, talon's cusp, hypodontia, impacted teeth, over-retained teeth and supernumerary teeth favored the maxilla when compared to the mandible.

Some anomalies are of esthetic concern, which may psychologically and socially affect the individual and hence need to be diagnosed and managed accordingly, while some cause lesions in the jaws leading to further complications and thereby need to be dealt with utmost concern. Certain anomalies of teeth cause malocclusions, which need to be diagnosed and treated at an early stage. Clinical and radiographic evaluation is the indispensable tool for early diagnosis and management.

\section{Acknowledgements}

Dr. Anupama A $\mathrm{S}^{1}$, Dr. Gunjan $\mathrm{C}^{2}$, Dr. Felicita ${ }^{3}$, Dr. Raghunath $\mathrm{D}^{4}$, Dr. Satyaprakash ${ }^{5}$.

1. Senior lecturer, Department of Oral Medicine and Radiology, Dr. Syamala Reddy Dental College \& Research Centre, Bangalore 2-5. PG student, Department of Oral Medicine and Radiology, PMNM Dental College and Hospital, Bagalkot.

\section{References}

[1] Kositbowornchai S, Keinprasit C, Poomat N. Prevalence and distribution of dental anomalies in pretreatment orthodontic Thai patients. K D J. 2010 July - December; 13(2):92-99.

[2] Ghaznawi HI, Dass H and Salako NO. A clinical and radiographic survey of selected dental anomalies and conditions in a Saudi Arabian population. The Saudi Dental J 1999 January-April; 11 (1):8-13.

[3] Ooshima T, Ishida R, Kenro M and Shizou S. The ccurrence of developmental anomalies of teeth and their association with tooth size in the primary and permanent dentitions of 1650 Japanese children. Int J of Pediatric Dentistry 1996; 6:87-94. http://dx.doi.org/10.1111/j.1365-263X.1996.tb00218.x.

[4] King N M, Tsai J.S.J. and Wong H.M. Morphological and Numerical Characteristics of the Southern Chinese dentitions. Part I: Anomalies 
in the Permanent Dentition. The Open Anthropology Journal 2010; 3:54-64. http://dx.doi.org/10.2174/1874912701003020054.

[5] Altug-Atac TA, Erdem D. Prevalence and distribution of dental anomalies in orthodontic patients. Am J Orthod Dentofacial Orthop 2007; 131 (4):510-514. http://dx.doi.org/10.1016/j.ajodo.2005.06.027.

[6] Kayal L and Jayachandran S. prevalence and distribution of dental anomalies in general population- an observational study. JIDA 2011May; 5 (5):612-615.

[7] Gupta S K, Saxena P, P Jain S and Jain D. Prevalence and distribution of selected developmental dental anomalies in an Indian population. Journal of Oral Science, Vol. 53, No. 2, 231-238, 2011. http://dx.doi.org/10.2334/josnusd.53.231.

[8] Sener S, Bozdağ G and Ünlü N. Presence, distribution, and association of dental anomalies: a clinical and radiographical study. Clinical Dentistry and Research 2011; 35 (3):43-52.

[9] Ghabanchi J, Haghnegahdar AA, Khodadazadeh Sh, Haghnegahdar S A radiographic and clinical survey of dental anomalies in patients referring to Shiraz Dental School. Shiraz Univ Dent J 2010; 10 Supplement.

[10]Nayak P, Nayak S. Prevalence and distribution of dental anomalies in 500 Indian school children. Bangladesh Journal of Medical Science. 2011 Jan; 10 (1):41-44. http://dx.doi.org/10.3329/bjms.v10i1.7318

[11]Guttal K S, Naikmasur V G, Bhargavac P, Bathid R J. Frequency of Developmental Dental Anomalies in the Indian Population. Eur J Dent 2010; 4:263-269.

[12]Cho Y S, Ki Y, Chu V, Lee C K.An audit of concomitant dental anomalies with maxillary talon cusps in a group of children fromHong Kong Primary Dental Care 2008;15(4):153-156 http://dx.doi.org/10.1308/135576108785891060.

[13] Goya HA, Tanaka S, Maeda T, Akimoto Y. An orthopantomographic study of hypodontia in the permanent teeth of Japanese pediatric $\begin{array}{lllll}\text { patients. } \mathbf{J} \text { of Oral Sciences 2008; } 50 & \text { (2):143-150 }\end{array}$ http://dx.doi.org/10.2334/josnusd.50.143.

[14]Berrocal MIL, Morales JFM, Gonzalez JMM. An observational study of the frequency of supernumerary teeth in a population of 2000 patients. Med Oral Pathol Oral Cir Buccal 2007; 12:E134-138.

[15]Vibhute AH, Vibhute NA and Daule R. Prevalence of dental anomalies in pre -treatment orthodontic patients in Western Maharashtra, India: an epidemiological study. Journal of orthodontic research 2013 May - August; 1 (2):66-69.

[16]Buenviaje TM, Rapp R. Dental anomalies in children: a clinical and radiographic survey. J of Dentistry for Children 1984; Jan-Feb: 42-46.

[17]Clayton JM. Congenital dental anomalies occurring in 3,557 children. J of Dentistry for children 1956; 23:206-208.

[18]Lestari Z.D, Wibowo T.B, Pradopo S The prevalence of over retained primary teeth and malocclusion in 612 years old children. Indonesian Pediatric Dental Journal 2010; 2. 